\title{
Control of an irrigation branch canal using model predictive controller
}

\author{
Jailakshmi Menon ${ }^{1, *}$, B. V. Mudgal' ${ }^{2}$ M. Guruprasath ${ }^{3}$ and S. Sivalingam ${ }^{4}$ \\ ${ }^{1}$ Saveetha Engineering College, Anna University, Chennai 602 105, India \\ ${ }^{2}$ Centre for Water Resources, Anna University, Chennai 600 025, India \\ ${ }^{3}$ Smarta Opti Solutions, Chennai 600 073, India \\ ${ }^{4}$ Public Works Department, Coimbatore 641 001, India
}

\begin{abstract}
Sustainable use of the available water resource is an important challenge for food security. An irrigation canal system consists of a number of pools connected to each other by control structures. Unsteady flow Saint-Venant equations are used to model the flow in the canal system and these equations are solved using implicit finite difference methods. The canal system is represented as linear time invariant system and the resulting equations are the dynamic equations in state space form. These linearized equations are modelled in Matlab ${ }^{\circledR}$ environment. The control strategy adopted in this research is the downstream control method of operation and the control structures adopted are radial gates and modified radial gates. The unsteady flow model is applied to the chosen study area and the results obtained from the model are used to simulate the dynamics of the canal system using model predictive controller toolbox. The results show that any closed loop controller will work efficiently with the hydraulic model developed.
\end{abstract}

Keywords: Finite difference, irrigation channels, linear time invariant, model predictive controller, unsteady flow.

ADVANCEMENT in low-cost controllers along with the development in telemetry equipment has paved the way for centralized automatic irrigation channels throughout the world. Modernization and regulation of irrigation canals with community participation is a proven method of increasing efficiency of the irrigation projects ${ }^{1}$. It can also improve the quality of service to water users, allowing crop diversification and alternate field irrigation techniques. Operation of gates in irrigation canals relies predominantly on manual techniques in most of the countries. Accounting for flow changes and disturbances using manual control is a time consuming and error-prone process $^{2}$. Automation of canals ensures better flow regulation in irrigation water delivery system. Researchers have developed numerous models and algorithms for automatic operation of sluice gates right from its inception in 1966 by the USBR.

\footnotetext{
*For correspondence. (e-mail: jailakshmiunni@gmail.com)
}

The flow in irrigation channels can be best described by the Saint-Venant equations of continuity and momentum which are nonlinear hyperbolic partial differential equations. The solutions to these equations can be obtained by numerical methods like finite difference approximation. Several authors have proposed different types of models to incorporate Saint-Venant equations for automatic control. Malaterre and Baume described various control algorithm models for solving the unsteady flow equations ${ }^{3}$. ASCE formed a task committee to test and evaluate the performance of canal automation algorithms on two test canals ${ }^{4}$. The finite difference model was used by many researchers, including Balogun et al. ${ }^{5}$ and Reddy ${ }^{6}$. In this method, the spatial derivatives of the unsteady flow equations are discretized using finite difference approximations and it is further linearized about the equilibrium conditions. Multi-input multioutput (MIMO) state space model was used by Seatzu ${ }^{7,8}$, Seatzu and Usai ${ }^{9}$. Qing-Song and Yang $^{10}$ presented a matrix approach to obtain the linear model of open channel system. Another model developed was to numerically compute the frequency response of the Saint-Venant equation linearized about any stationary regime ${ }^{11,12}$.

Model predictive controller (MPC) is used for water quantity control in open channels. Early examples of its applications for canal control can be found in van Overloop ${ }^{13}$, Sepulveda ${ }^{14}$. Wahlin and Clemmens ${ }^{2}$ applied MPC to the branching canal network. Modified state space integrator delay model was used to describe the canal dynamics. The results of MPC are compared with conventional feedback control and feed forward control. The controllers were applied on actual irrigation canals in real-time. The results showed that MPC performed better than conventional controllers. Series of proportional integral controller took a longer time for the water levels to settle than the linear quadratic regulator. Linear quadratic regulator describes the system dynamics using linear equations and the theory of optimal control is used to solve these equations. Weyer ${ }^{15}$ and Ooi and Weyer ${ }^{16}$ proposed a decentralized PI controller with a first-order low pass filter. The model was a frequency domain model and it considered two types of configurations, i.e. with feed forward from downstream gate and without feed forward 


\section{RESEARCH ARTICLES}

from the downstream gate. Horvath et al. ${ }^{17}$ compared the performance of MPC using gate opening and discharge as the control variable. The results were experimentally tested in a laboratory canal. The results showed that the gate opening was better performing as a control variable. Dynamic target trajectory method was proposed to calculate the set point during the simulation period when there was a mismatch between supply and demand ${ }^{18}$. The calculations are based on the volume of mismatch spread over the available capacity in each pool. Set point change was taken as an extra disturbance at each time step. This offered a correction of water level deviation, which in turn softens system constraints in the optimization technique. Since the mismatch in demand is spread throughout the canal system, the water levels can be better controlled. The approach was applied to central main canal in Arizona. Tuning process in MPC is largely simplified in the algorithm and it leads to better control performance.

The literature shows that MPC is simpler and better from an implementation perspective when compared to other types of conventional controllers. Hence it is adopted in the present study to control the irrigation canal system.

Attempts for automating canals have been made in a few irrigation systems in India. History of canal automation case studies in India is a mixed bag. Renewed efforts are being made by instrumentation of the canal systems. Canal automation was successfully implemented as a pilot project in a stretch of Thondamuthur branch canal which takes off from Parambikulam Main Canal of the Parambikulam Aliyar basin in South India. Total channel control is the concept introduced and patented by Rubicon, Australia. This is based on the 'demand' driven philosophy, where the control system reacts to replenish customer demand. The pilot project performed well during the period 2007-09. Hence the same branch canal is adopted in the present study to test the performance of MPC controller.

Radial gates are widely used for controlling the flow in irrigation channels. The discharge characteristics of the radial gates show large variations in submerged flow conditions. Menon and Mudgal ${ }^{19}$ conducted experiments to determine the discharge coefficient for radial gates under free and submerged flow conditions. The discharge characteristics of the radial gates were improved by suppressing the formation of vena-contracta at the exit of the radial gate. Accordingly, quadrants of an ellipse with three different dimensions were attached at the lip of the radial gate. The geometry of the modified gate and their dimensions are shown in Figure 1. The modified geometry with a ratio of $1: 5$ between the semi-major axis of the quadrant to the radius of the gate was found to have better discharge characteristics as the contraction coefficient $C_{C}$ values were found to be higher in this case ${ }^{19}$. These radial gates with modifications are used to control the canals using MPC in the chosen study area.

The Saint-Venant equations are modelled in the Matlab ${ }^{\circledR}$ environment and the control of gates is accom- plished by using MPC. This study compares the performances of radial gates and the modified radial gate in controlling the sluice gate operation using MPC.

\section{Theoretical background of flow in an irrigation canal system}

An irrigation canal is composed of series of interconnected canal pools or reaches. The upstream and downstream ends of the canal are assumed to be bounded by constant level reservoirs. The number of pools in a canal varies for each system. Each canal pool is divided into a definite number $(N-1)$ of segments of length $\Delta x$ with $N$ nodal points. Each pool has control structures at the upstream and downstream end. These control structures can be sluice gates or weirs. The offtake points can be located anywhere in the pool, but in this study, it is assumed to be located at the downstream end of the pool very close to the downstream control structure. The cross-section of the canal is assumed to be trapezoidal in shape and the control structures are radial gates. The schematic sketch of the canal pools is given in Figure 2.

\section{Methodology}

\section{Governing equations}

Flow in irrigation canals can be completely described by the unsteady flow Saint-Venant equations of continuity and momentum ${ }^{20}$.

Continuity equation

$$
\frac{\partial y}{\partial t}+\frac{1}{T} \frac{\partial Q}{\partial x}+\frac{q}{r}=0
$$

Momentum equation

$$
\frac{\partial Q}{\partial t}-\frac{Q^{2}}{A^{2}} \frac{\partial A}{\partial x}+\frac{2 Q}{A} \frac{\partial Q}{\partial x}+g A\left\{\frac{\partial y}{\partial x}-S_{o}+S_{f}\right\}+q v=0
$$

where $y$ is the depth of water in $\mathrm{m}, T$ the top width of the channel at the water surface in $\mathrm{m}, Q$ the flow rate in the

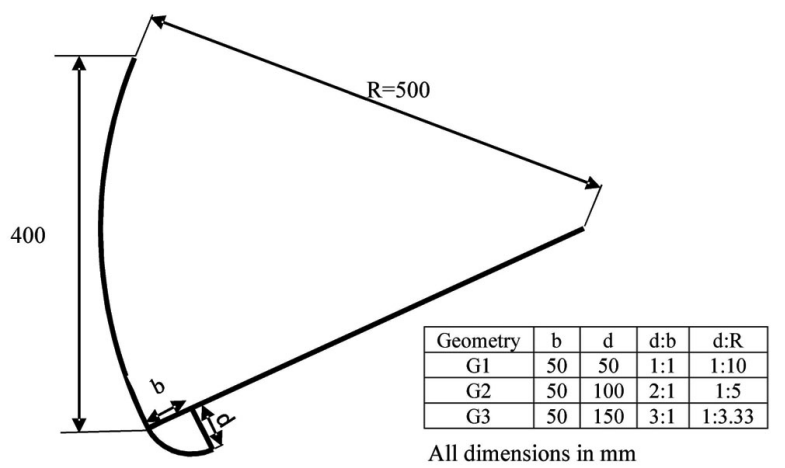

Figure 1. Dimensions of the modified radial gate ${ }^{19}$.

CURRENT SCIENCE, VOL. 118, NO. 8, 25 APRIL 2020 


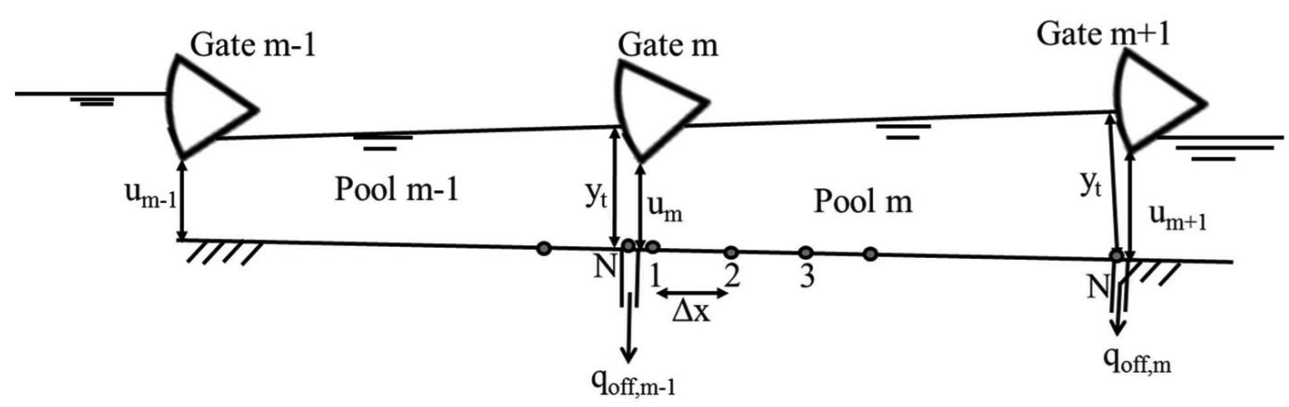

Figure 2. Schematic sketch of the canal pools.

channel in $\mathrm{m}^{3} / \mathrm{s}, x$ the longitudinal distance in the flow direction in $\mathrm{m}, q$ the lateral outflow per unit length of the channel in $\mathrm{m}^{2} / \mathrm{s}, v$ the velocity in $\mathrm{m} / \mathrm{s}, A$ the wetted cross-sectional area, $g$ the acceleration due to gravity $\left(9.81 \mathrm{~m} / \mathrm{s}^{2}\right), S_{o}$ the channel bottom slope and $S_{f}$ is the friction slope of the canal.

Equations (1) and (2) are hyperbolic partial differential equations and can be solved by numerical methods. The boundary conditions at both the ends of the canal system need to be specified in order to solve the equations of continuity and momentum. These equations are valid within each canal pool. At the upstream and downstream section of the pool, where the sluice gates are located, the flow continuity equation and the gate discharge equations are applied (Figure 2).

Flow continuity equation at the downstream node $(N)$ of pool $(m-1)$

$$
Q_{N, m-1}=Q_{1, m}+q_{o f f, m-1},
$$

where $Q_{N, m-1}$ is the discharge at the downstream node $(N)$ in pool $(m-1), Q_{1, m}$ the discharge at the upstream node in pool, $q_{\text {off }, m-1}$ the off take discharge in pool $(m-1)$ in $\mathrm{m}^{3} / \mathrm{s}, m$ the pool index and varies from $1, \ldots, M, M$ the total number of pools in the canal system and $N$ is the last node of each pool.

Gate discharge equation at the upstream node (1) of pool $m$

$$
Q_{1, m}=C_{d, m} * b_{g, m} * u_{m} * \sqrt{2 g \Delta h},
$$

where $C_{d, m}$ is the coefficient of discharge of the gate $m$, $u_{m}$ the sluice gate opening in $\mathrm{m}, b_{g, m}$ the width of the gate $m$ in $\mathrm{m}, g$ is the acceleration due to gravity and

$$
\Delta h=y_{N, m-1}-y_{1, m},
$$

where $y_{N, m-1}$ is the depth of flow at node $N$ in pool $m-1$ and $y_{1, m}$ is the depth of flow at node 1 in pool $m$.

The unsteady flow model developed in this research is based on the above four eqs (1)-(4) applied appropriately at each of the nodes. The spatial derivative terms in the continuity and momentum equations are discretized using finite difference approximations ${ }^{5}$. Forward difference scheme is used to discretize the continuity equation at the upstream node and backward difference scheme is applied at the downstream node. As the upstream node and downstream node specifies the boundary condition of the pool, the continuity equation alone is considered at these nodal points. These nodes are very close to the control gates and hence gate discharge equations are valid at these points. Hence, appropriate form of the gate discharge equations are substituted for the discharge in continuity equation at the first and last node of the pool. Central difference scheme is used to discretize the continuity and momentum equations for all interior nodes, so that the effects of adjacent nodes are not neglected. Applying the method described above, the following equations are obtained.

\section{Upstream node in each pool}

Equation of continuity

$$
\frac{\mathrm{d} y_{1, m}}{\mathrm{~d} t}+\frac{Q_{2, m}-Q_{g, m}}{T_{1, m} \Delta x}=0,
$$

where $Q_{2, m}$ is the discharge at node 2 in pool $m, Q_{g, m}$ the gate discharge equation (4), $T_{1, m}$ the top width of the channel at the water surface at node 1 in pool $m, y_{1, m}$ the depth of flow at node 1 in pool $m$ and $\Delta x$ is the longitudinal distance between adjacent nodes.

\section{Downstream node in each pool}

Equation of continuity

$$
\frac{\mathrm{d} y_{N, m}}{\mathrm{~d} t}+\frac{Q_{N-1, m}-Q_{g, m+1}}{T_{N, m} \Delta x}+\frac{q_{N, m}}{T_{N, m} \Delta x}=0,
$$

where $y_{N, m}$ is the depth of flow at node $N$ in pool $m, \mathrm{Q}_{g, m+1}$ the gate discharge equation, $Q_{N-1, m}$ the discharge at node $N-1$ in pool $m, T_{N, m}$ the top width of the channel at the 


\section{RESEARCH ARTICLES}

water surface at node $N$ in pool $m$ and $q_{N, m}$ is the offtake discharge at node $N$ in pool $m$ in $\mathrm{m}^{3} / \mathrm{s}$.

$$
Q_{g, m+1}=C_{d, m+1} * b_{g, m+1} * u_{m+1} * \sqrt{2 g \Delta h}
$$

where $C_{d, m+1}$ is the coefficient of discharge of the gate $m+1, b_{g, m+1}$ the width of the gate $m+1$ in $\mathrm{m}, u_{m+1}$ is the opening of the gate in $\mathrm{m}$ and

$$
\Delta h=y_{N, m}-y_{1, m+1},
$$

$y_{N, m}$ is the depth of flow at node $N$ in pool $m$ and $y_{1, m+1}$ is the depth of flow at node 1 in pool $m+1$.

\section{Interior nodes}

Equation of continuity

$$
\frac{\mathrm{d} y_{j, m}}{\mathrm{~d} t}+\frac{Q_{j+1, m}-Q_{j-1, m}}{T_{j, m} * 2 * \Delta x}=0 \quad(\text { for } j=2,3, \ldots, N-1),
$$

where $y_{j, m}$ is the depth of flow at node $j$ in pool $m, Q_{j+1, m}$ the discharge at node $j+1$ in pool $m, \mathrm{Q}_{j-1, m}$ the discharge at node $j-1$ in pool $m$ and $T_{j, m}$ is the top width of the channel at the water surface at node $j$ in pool $m$.

Equation of momentum

$$
\begin{aligned}
& \frac{\mathrm{d} Q_{j, m}}{\mathrm{~d} t}-\frac{Q_{j, m}^{2}}{A_{j, m}^{2}} * \frac{\left(A_{j+1, m}-A_{j-1, m}\right)}{2 * \Delta x} \\
& +\frac{2 Q_{j, m}}{A_{j, m}} * \frac{\left(Q_{j+1, m}-Q_{j-1, m}\right)}{2 * \Delta x} \\
& +g * A_{j, m}\left\{\frac{\left(y_{j+1, m}-y_{j-1, m}\right)}{2 * \Delta x}-S_{0, m}+S_{f, m}\right\}=0 \\
& \quad(\text { for } j=2,3, \ldots, N-1),
\end{aligned}
$$

where $Q_{j, m}$ is the discharge at node $j$ in pool $m, A_{j+1, m}$ the wetted cross sectional area at node $j+1$ in pool $m, A_{j-1, m}$ the wetted cross sectional area at node $j-1$ in pool $m$, $y_{j+1, m}$ the depth of flow at node $j+1$ in pool $m, y_{j-1, m}$ the depth of flow at node $j-1$ in pool $m, S_{o}$ the channel bottom slope and $S_{f}$ is the friction slope.

In the case of node 2 and $N-1$, the discharge $Q_{2, m}$ and $Q_{N-1, m}$ are replaced with the appropriate forms of the gate discharge equations. These discretized equations are nonlinear differential equations and hence need to be linearized about the equilibrium condition.

In canals, the system characteristics are very gradual and so the time invariant systems can be approximated to linear time invariant (LTI) system. In this study, the state variables chosen are the discharge and the depth of flow and the gate opening is considered as the control variable. Different control variables are possible in open channel systems. When gate openings are used as control variables, the controller calculates the gate openings and sends the information to the actuator. If the discharge is used as a control action variable, the controller calculates the gate openings based on the discharge. Horvath et al. ${ }^{17}$ studied on short pools with MPC and found that the uses of gate openings as a manipulated variables are more beneficial than the discharge as a manipulated variable in centralized controllers. It is also possible to put constraints on the gate openings, which are important to the limitations of the physical system. The controlled variable is the depth of flow at the downstream end of each pool (i.e. distant downstream control).

\section{Equilibrium (steady state) conditions}

When gate openings remain constant for a long period of time, the depths and discharge in the canal approach steady state conditions. The nonlinear equations need to be linearized about this equilibrium condition. The linearized equations can then be used to simulate the dynamic response of the canal system. The steady state equilibrium condition for a particular irrigation schedule can be obtained using the dynamic equation of gradually varied flow.

$$
\frac{\mathrm{d} y}{\mathrm{~d} x}=\frac{S_{o}-S_{f}}{1-\frac{Q^{2} T}{g A^{3}}},
$$

where $\mathrm{d} y / \mathrm{d} x$ represents the water surface slope relative to the channel bottom.

The computations are started from the downstream end of the last pool and the equilibrium gate opening is determined using the constant downstream reservoir depth and the target depth at the downstream end of the pool. The backwater profile is determined using eq. (12) and the depths and discharge at each of the node are hence calculated. The depths and discharge computed represent the steady state equilibrium values at each of the nodes. The process is repeated up to the first pool of the canal system. The discretized equations are linearized further about the steady state values.

\section{Linearized unsteady flow model}

Let the equilibrium depth, discharge and gate opening in the canal pool be $y_{j, m}^{e}, Q_{j, m}^{e}$ and $u_{m}^{e}$ respectively. Let the actual values of these parameters be $y_{j, m}, Q_{j, m}$ and $u_{m}$. The difference between the actual and steady state values (perturbations) are given by 


$$
\begin{aligned}
& \delta y_{j, m}=y_{j, m}-y_{j, m}^{e}, \\
& \delta Q_{j, m}=Q_{j, m}-Q_{j, m}^{e}, \\
& \delta u_{m}=u_{m}-Q_{m}^{e},
\end{aligned}
$$

where $j$ is the node index and $m$ is the pool index.

Applying the multivariable Taylor series expansion to each term of the discretized equation about the equilibrium points and truncating the higher-order terms results in linear ordinary differential equations in the perturbed quantities for the nodal points of the form

$$
\frac{\mathrm{d}}{\mathrm{d} t} \delta z(t)=A * \delta z(t)+B * \delta u(t)
$$

where $A$ and $B$ are the Jacobian matrices evaluated at the equilibrium condition and $\delta z(t)$ and $\delta u(t)$ are the perturbations from the equilibrium states.

$$
\begin{aligned}
& \delta z(t)=\left[\delta y_{1,1}, \delta y_{2,1}, \delta Q_{2,1}, \ldots, \delta Q_{N-1, m}, \delta y_{N, m}\right]^{T}, \\
& \delta u(t)=\left[\delta u_{1}, \delta u_{2}, \ldots, \delta u_{m+1}\right]^{T},
\end{aligned}
$$

where $N$ is the number of nodes in the pool, $m$ is the number of pools in the system. These equations (16)-(18) are solved in Matlab ${ }^{\circledR}$ environment and the matrices $A$ and $B$ are obtained as outputs from the model.

\section{Control strategy}

The control strategy adopted is downstream control. In the downstream method of control, the target depth is fixed at the downstream end of the pool and the observation is made at that section. The error in the water level, if any, will be eliminated by adjusting the gate opening on the upstream side ${ }^{21}$. Figure 3 shows the configuration of the downstream control strategy.

The control strategy adopted for irrigation canals will be effective only if we can accurately control the system. Closed loop control system monitors its output, compares the actual output with the desired output and feeds it back so as to reduce the error and if disturbed, bring the output of the system back to the original or desired response.

\section{Data description}

The canal system selected for implementing the MPC controller is the idealized branch canal of the Parambikulam Aliyar basin. The Thondamuthur branch canal which takes off from Parambikulam Main Canal (PMC) is $12.655 \mathrm{~km}$ long with a command area of 4286 ha and it is divided into four pools based on the topographic features (canal bottom slope) of the canal system. This branch canal represents any medium-sized irrigation canal system and hence the model can be applied to any of the irrigation canal networks with suitable modifications. The entire command area in this branch canal is divided into 4 zones and water is allocated to each zone once in two years. Zone I has a total command area of 5286.33 acres (2139.3 ha) and water is diverted to this zone in two shifts. In the first shift, an area of 2384.33 acres (964.9 ha) is irrigated and the remaining area of 2902 acres is irrigated in the second shift. Figure 4 represents the schematic configuration of this branch canal system.

The number of pools chosen is four with radial gates as the control structures at the upstream and downstream end of each pool. The water demand in a pool is lumped into a single off take at the downstream end of the pool so that the developed model can be effectively applied to the study area. The hydraulic particulars of Thondamuthur branch canal and the irrigation water requirement for the first shift is tabulated in Table 1. The depth of flow in PMC is $2.7 \mathrm{~m}$ at full supply and the same is used for modelling purpose. The target depth at the downstream end of the pool is fixed based on the off take water requirement at the downstream end of the pool. The gate discharge coefficient is taken as 0.65 and the widths of the gate are $1.6,1.6,1.1,0.6$ and $0.4 \mathrm{~m}$ respectively, for gate1 to gate 5 .

The data set in Table 1 serves as the input to the steady state model for the computation of the equilibrium condition in each pool using the gradually varied flow equation (12).

In irrigation channels, there may be perturbations in the discharge and depth due to change in the control structure opening or due to extraction or augmentation of flow in the canals. Hence it is necessary to have closed loop control systems to bring back the canal systems to stability.

The goal of the MPC in centralized systems is to have a model that is able to describe the whole system dynamics. In this research, all the canal pools are assumed to be affected by backwater and hence any disturbance at the downstream end will be reflected at the upstream end of the canal. Parambikulam Aliyar Project (PAP) basin is

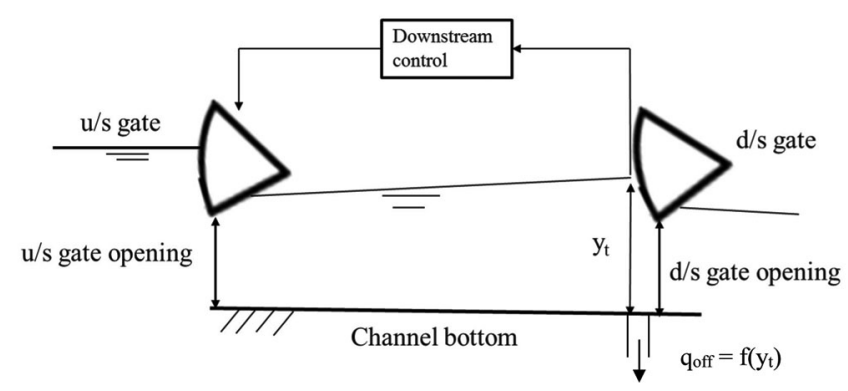

Figure 3. Configuration of downstream control strategy. 


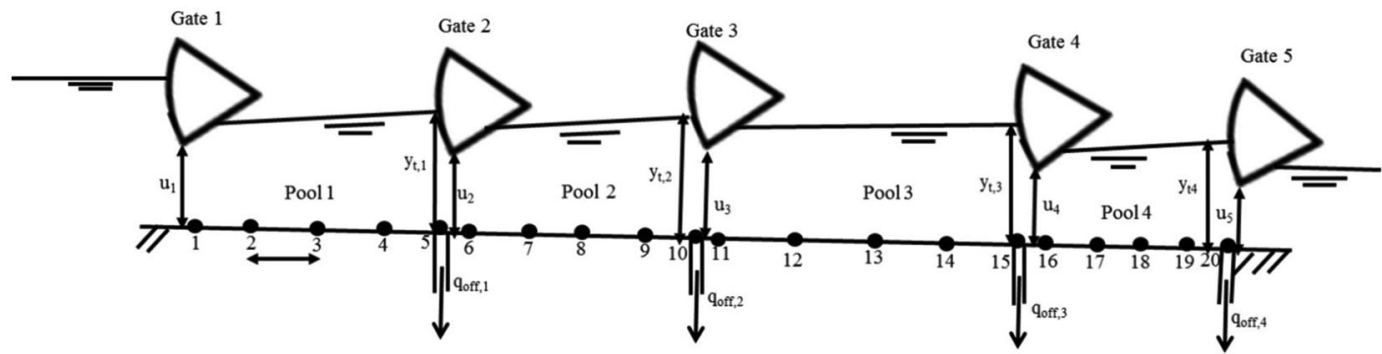

Figure 4. Schematic configuration of the Thondamuthur branch canal.

Table 1. Hydraulic particulars of Thondamuthur branch canal (idealized for the model)

\begin{tabular}{|c|c|c|c|c|}
\hline Hydraulic particulars & Canal pool 1 & Canal pool 2 & Canal pool 3 & Canal pool 4 \\
\hline Length of the pool (m) & 2670 & 3930 & 4565 & 1490 \\
\hline Upstream water level in the PMC (m) & 2.7 & - & - & - \\
\hline Downstream reservoir height $(\mathrm{m})$ & - & - & - & 0.6 \\
\hline Bottom width of the trapezoidal channel (m) & 1.6 & 1.1 & 0.6 & 4 \\
\hline Side slope of the channel & $1: 1$ & $1: 1$ & $1: 1$ & $1: 1$ \\
\hline Bottom slope of the channel & 0.00047 & 0.00052 & 0.00066 & 0.0011 \\
\hline Manning's roughness coefficient & 0.016 & 0.016 & 0.016 & 0.016 \\
\hline Discharge in the pool $\left(\mathrm{m}^{3} / \mathrm{s}\right)$ & 1.12 & 0.755 & 0.447 & 0.185 \\
\hline Offtake discharge at the $\mathrm{d} / \mathrm{s}$ end of the pool $\left(\mathrm{m}^{3} / \mathrm{s}\right)$ & 0.365 & 0.308 & 0.262 & 0.081 \\
\hline Target depth at the downstream end of the pool (m) & 0.75 & 0.85 & 0.9 & 0.94 \\
\hline
\end{tabular}

Table 2. Hydraulic particulars of the canal pools for the new equilibrium condition

\begin{tabular}{lllll}
\hline Hydraulic particulars & Pool 1 & Pool 2 & Pool 3 & Pool 4 \\
\hline Offtake discharge at the d/s end of the pool $\left(\mathrm{m}^{3} / \mathrm{s}\right)$ & 0.33 & 0.2772 & 0.2358 \\
Target depth at the downstream end of the pool $(\mathrm{m})$ & 0.65 & 0.7 & 0.8 & 0.84 \\
\hline
\end{tabular}

water deficient most of the time. A test case scenario is created so that there is a decrease of $10 \%$ discharge in the canal. The scenario will help to analyse the performance of the MPC controller in situations of water shortage. This decrease is proportionately distributed between all the reaches of the canal system so that equity in water distribution is attained. Accordingly, the model calculated the new set point targets for the downstream depths in each of the pool. The decreased discharge and the target depths obtained from the model for the four pools are tabulated in Table 2 .

\section{Model predictive control}

The optimization problem can be described by eq. (19) as given in MPC user's guide ${ }^{22}$.

$$
\begin{array}{r}
\min _{\Delta u(k \mid k, \ldots, \Delta u(M-1+k \mid k), \varepsilon}\left(\sum _ { i = 1 } ^ { P - 1 } \left[\sum_{j=1}^{n_{y}} \mid w_{i+1, j}^{y}\left(y_{j}(k+i+1 \mid k)\right.\right.\right. \\
\left.\left.-\left.y_{t, j}(k+i+1)\right|^{2}+\left.\sum_{j=1}^{n_{u}}\left|w_{i, j}^{\Delta u} \Delta u_{j}(k+i)\right| k\right|^{2} \mid\right]\right)+\rho_{\varepsilon} \varepsilon^{2},
\end{array}
$$

where the subscript ()$_{j}$ denotes the $j$ th component of the vector, $w_{i+1, j}^{y}$ and $w_{i, j}^{\Delta u}$ are the non-negative weights of the corresponding variables, $(k+i \mid k)$ denotes the value predicted for time $k+i$ based on the information available at time $k, y_{\mathrm{t}}(k)$ is the current sample of the output reference subject to

$$
\begin{aligned}
& u_{j \min }(i)-\varepsilon v_{\text {jmin }}^{u}(i) \leq u_{j}(k+i \mid k) \leq u_{\text {jmax }}(i)+\varepsilon v_{\text {jmax }}^{u}, \\
& \Delta u_{\text {jmin }}(i)-\varepsilon v_{\text {jmin }}^{\Delta u}(i) \leq \Delta u_{j}(k+i \mid k) \leq \Delta u_{\text {jmax }}(i)+\varepsilon v_{\text {jmax }}^{\Delta u},
\end{aligned}
$$

$$
y_{\text {jmin }}(i)-\varepsilon v_{\text {jmin }}^{y}(i) \leq y_{j}(k+i+1 \mid k) \leq y_{\text {jmax }}(i)+\varepsilon v_{\text {jmax }}^{y},
$$

$\Delta u(k+h) \mid k)=0$.

$$
i=0, \ldots, P-1 \text { and } h=M, \ldots, P-1 \text {. }
$$

where $P$ is the prediction horizon and $M$ is the control horizon. 
With respect to the sequence of input increments $\{\Delta u(k \mid k), \ldots, \Delta u(M-1+k \mid k)\}$ and to the slack variable $\varepsilon$ and by setting $u(k)=u(k-1)+\Delta u(k \mid k)^{*}$, where $\Delta u(k \mid k)^{*}$ is the first element of the optimal sequence.

$u_{\text {jmin }}, u_{\text {jmax }}, \Delta u_{\text {jmin }}, \Delta u_{\text {jmax }}, y_{\text {jmin }}, y_{\text {jmax }}$ are the lower and upper bounds on the corresponding variable, $\rho_{c}$ is the weight on slack variable $\varepsilon$, and $v_{\text {jmin }}^{u}, v_{\text {jmax }}^{u}, v_{\text {jmin }}^{\Delta u}, v_{\text {jmax }}^{\Delta u}$, $v_{j \text { min }}^{y}, v_{j \text { min }}^{y}$ are the equal concern for the relaxation vectors which represents the concern for relaxing the corresponding constraint. The algorithm implemented in the MPC toolbox uses the quadratic programming solver to solve the above equation.

There are four tuning parameters namely the prediction horizon $(P)$, the control horizon $(M)$, input (manipulated variable) weight and the output (controlled variable) weight out of which $P$ and $M$ are for MPC setting (one time tuning) based on model dynamics and the input weight and output weight are tuned based on the controller performance. The tuning was made based on the error variance and energy loss in the manipulated variable. The

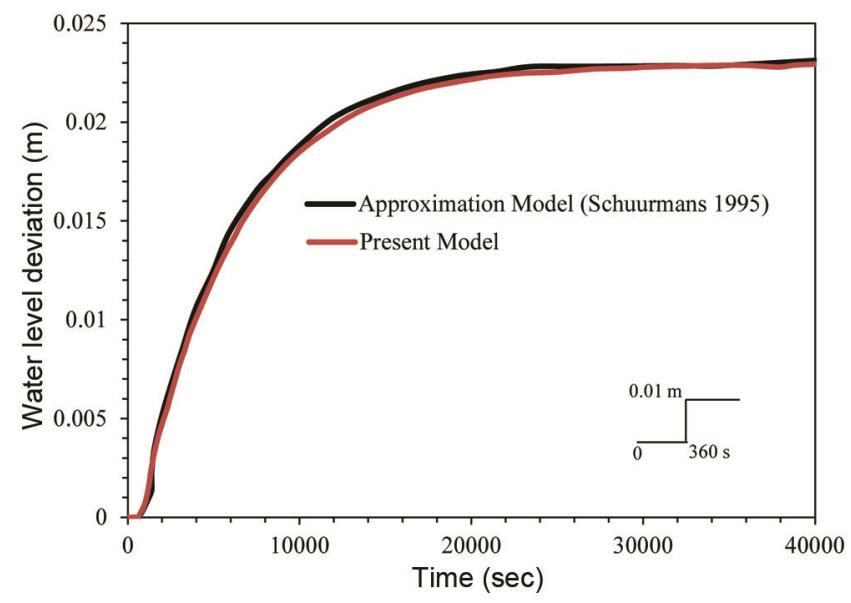

Figure 5. Comparison of step response obtained with the approximation model (Schuurmans et al. (1995) and the present model for single pool system.

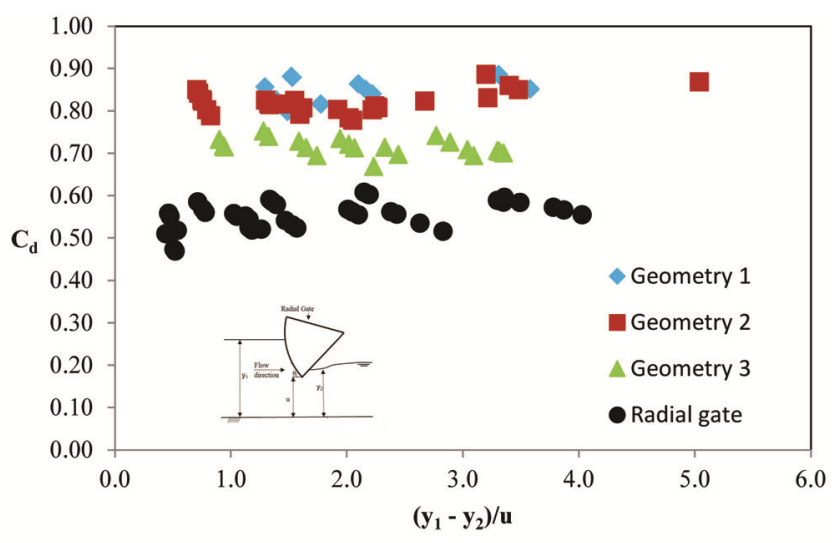

Figure 6. Coefficient of discharge with relative differential head in submerged flow. initial values of $P$ and $M$ were selected based on the open loop response of the canal pool system. Dead time is to include the transients when there is a disturbance or change in actuators. $M$ was chosen to be more than the dead time $(\sim 30 \mathrm{~min})$. Steady state of a system is attained at 3-4 times of slowest time constant. So we have chosen $P$ to be 5 times $M$, so that it will cover the complete steady state. More than five times is not recommended as it may degrade the performance of the controller. The control interval or the sampling period chosen is 0.1 . Different values of $P$ and $M$ were attempted and it was found that the controller performed better with a prediction horizon of 200 and the control horizon of 40 . The simulation time is 5000 sampling units. Input constraints are hard and are not violated during the simulation. The output constraints are assumed to be soft. The overall constraint softness is taken as 0.75 . The weights of all inputs are taken as zero, which implies that equal priority is given for all gates to be operated. The rate weight is chosen on the lower side $(0.1)$ so that the corresponding manipulated variable can move freely, provided that the constraints are satisfied. The weight column of the output variables sets a penalty on deviations of each output variable from its set point. All the target depths are given equal weightage in this model.

\section{Results and discussion}

The unsteady flow model was simulated to obtain the open loop step response and the pulse response of two hypothetical canal systems cited in the literature. The simulated results are compared with the results in the literature and are validated. The validation graph for the open loop step response is given in Figure 5.

The test cases were simulated to change the set point in the pools from the initial equilibrium condition (Table 1) to the new equilibrium values (Table 2). Since there is a $10 \%$ decrease in the flow rate, the target depth in pool 1 , pool 2, pool 3 and pool 4 are decreased by $0.1,0.15,0.1$ and $0.1 \mathrm{~m}$ respectively. The test cases were run under tuned condition with maximum and minimum gate opening constraint.

The simulation was performed by considering radial gates and modified radial gates as control structures in the pool. The experimental results ${ }^{19}$ showed that the discharge coefficient for radial gates under submerged conditions ranged from 0.55 to 0.65 , which is in close agreement with that of the results from Speerli and Hag$\mathrm{er}^{23}$. Hence the coefficient of discharge $C_{d}$ for radial gates under submerged flow is taken as 0.65 . In the case of submerged flow, the modified gate with geometry G2 performs better than the other gates and has a $C_{d}$ which ranges from 0.8 to 0.9 which is approximately 1.5 times that of the radial gates. Figure 6 depicts the variation of coefficient of discharge of radial gates and modified radial gates with differential depth of flow. 
Table 3. Model predictive controller (MPC) simulation results for inputs (gate opening)

\begin{tabular}{|c|c|c|c|c|c|}
\hline \multirow[b]{2}{*}{ Condition } & \multirow[b]{2}{*}{ Gate no. } & \multicolumn{2}{|c|}{ Radial gate } & \multicolumn{2}{|c|}{ Modified radial gate } \\
\hline & & $\begin{array}{l}\text { Time } \\
\text { (sampling units) }\end{array}$ & $\begin{array}{l}\text { Change in gate } \\
\text { opening }(\mathrm{m})\end{array}$ & $\begin{array}{l}\text { Time } \\
\text { (sampling units) }\end{array}$ & $\begin{array}{l}\text { Change in gate } \\
\text { opening }(\mathrm{m})\end{array}$ \\
\hline \multirow{5}{*}{$\begin{array}{l}\text { Tuned with maximum and minimum } \\
\text { gate opening constraint }\end{array}$} & 1 & 396 & -0.00297 & 327 & -0.00257 \\
\hline & 2 & 2126 & 0.1 & 1163 & 0.099 \\
\hline & 3 & 3162 & 0.09817 & 2321 & 0.045 \\
\hline & 4 & 3435 & 0.073 & 2799 & 0.042 \\
\hline & 5 & 3984 & 0.086 & 3932 & 0.0658 \\
\hline
\end{tabular}

Table 4. MPC simulation results for outputs (target water depths)

\begin{tabular}{lcccc}
\hline & & \multicolumn{2}{c}{ Time (sampling units) } & \\
\cline { 3 - 4 } Condition & Pool no & Radial gate & $\begin{array}{c}\text { Modified } \\
\text { radial gate }\end{array}$ & $\begin{array}{c}\text { Change in target } \\
\text { water level (m) }\end{array}$ \\
\hline Tuned with maximum and minimum & 1 & 427 & 371 & -0.1 \\
$\quad$ gate opening constraint & 2 & 544 & 495 & -0.15 \\
& 3 & 748 & 736 & -0.1 \\
& 4 & 452 & 431 & -0.1 \\
\hline
\end{tabular}
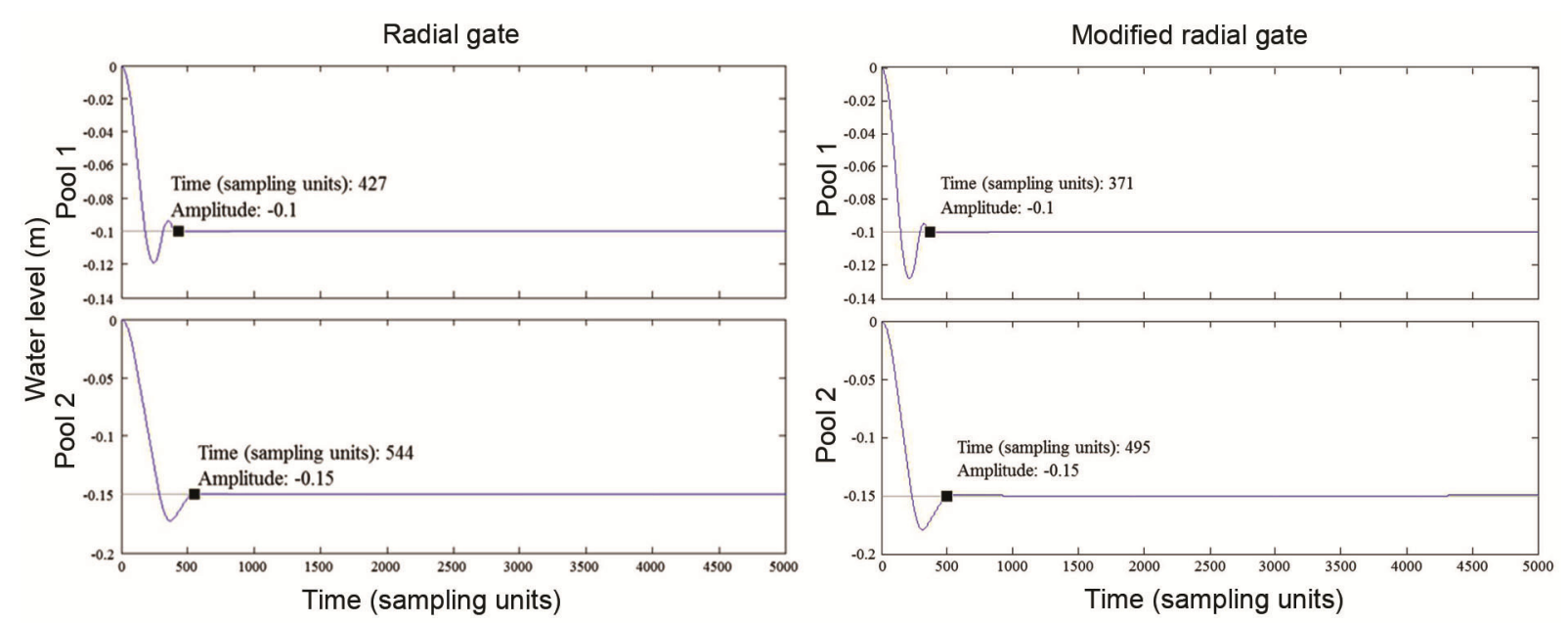

Figure 7. Level of the target depth in pools 1 and 2 under tuned condition with maximum and minimum gate opening constraint.
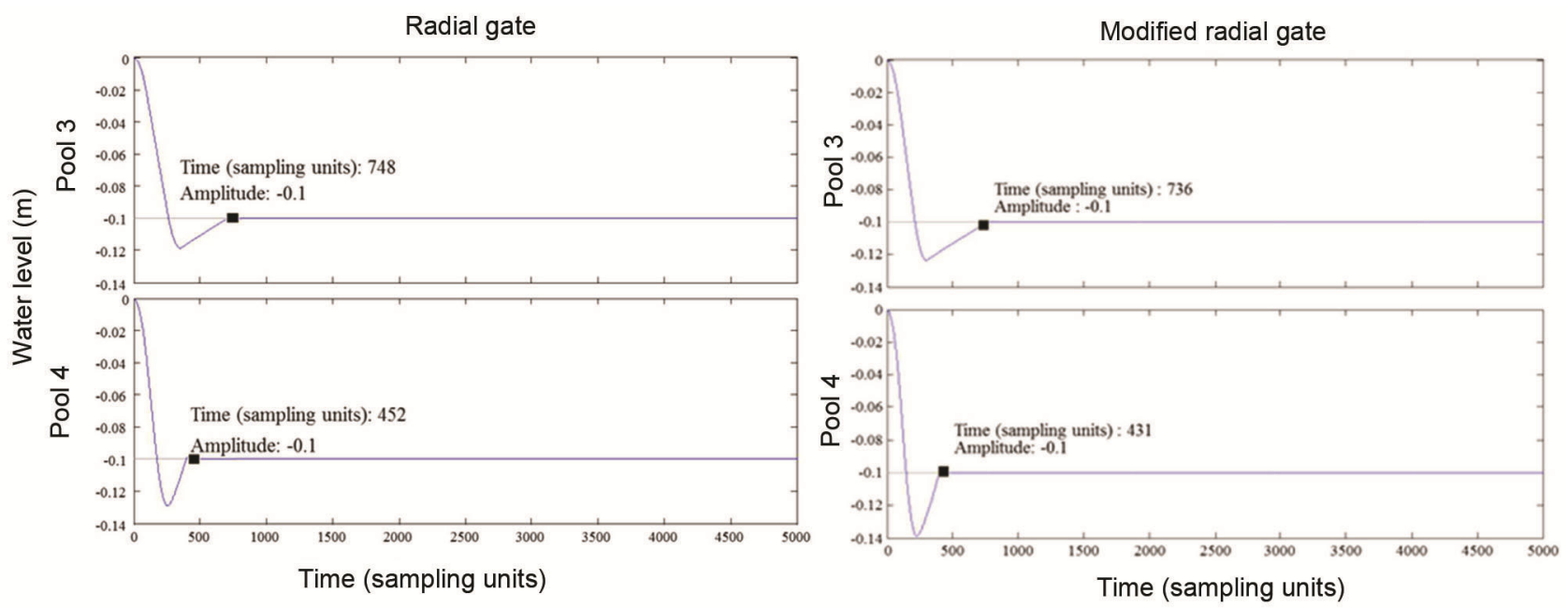

Figure 8. Level of the target depth in pools 3 and 4 under tuned condition with maximum and minimum gate opening constraint. 


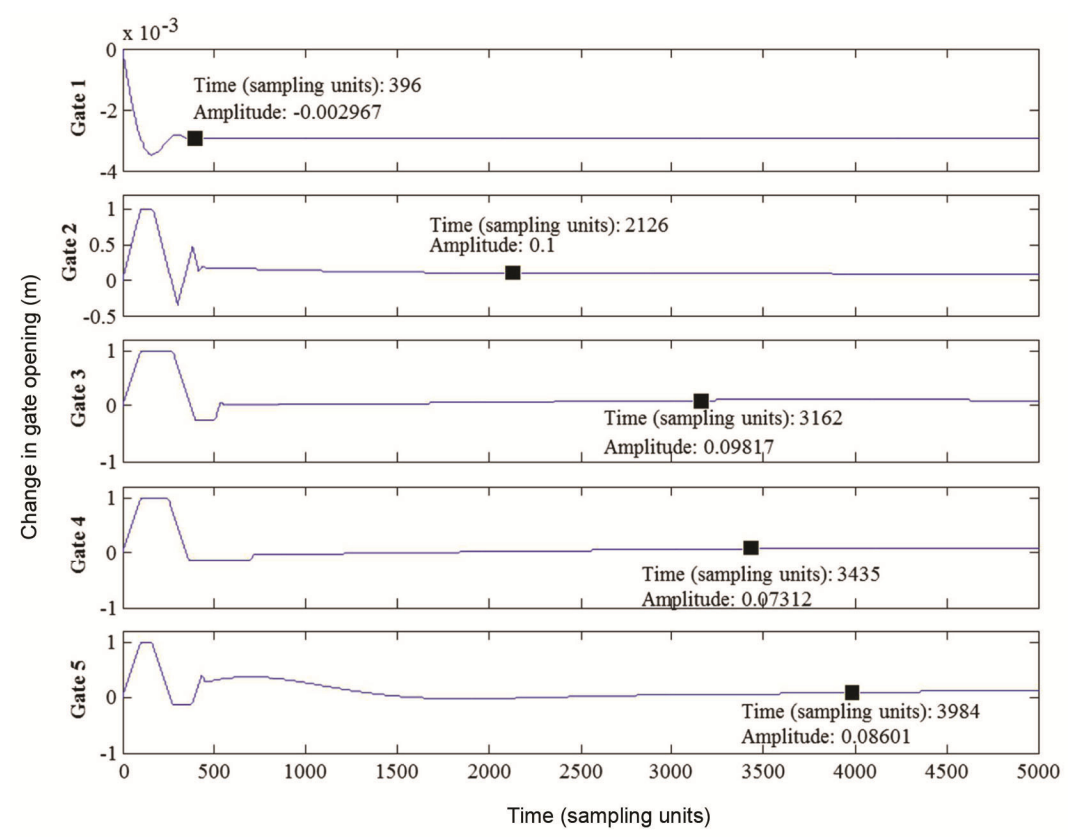

Figure 9. Change in gate opening under tuned condition with radial gates.

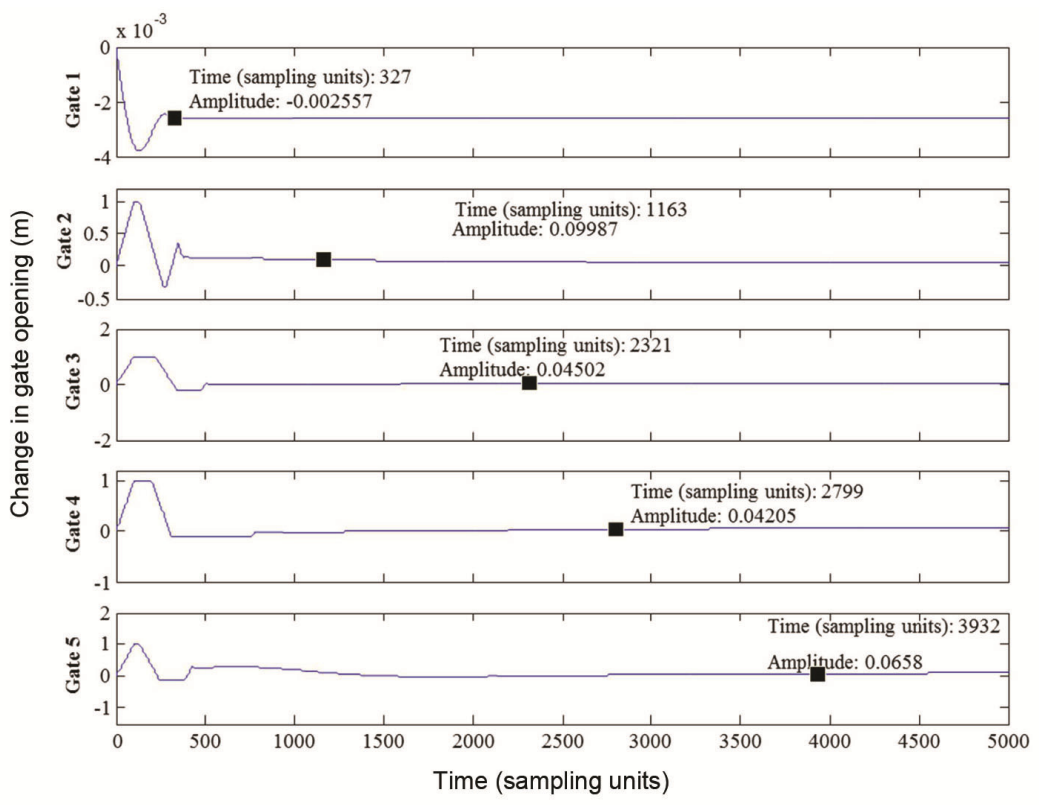

Figure 10. Change in gate opening under tuned condition with modified radial gates.

The model is simulated using MPC controller and the results are shown in the following figures. The canal system is stable under closed loop conditions as can be seen from Figures 7-10 which depicts the water level changes in the target depth and change in gate opening required for the steady state equilibrium condition for radial gates and modified radial gates. The results are consolidated in Tables 3 and 4.

The time taken for the target depth in pool 1 to attain equilibrium is 427 time units with radial gates. It is 1.2 times faster in the case of modified radial gates as can be seen in Figure 7. Similarly in pools 2, 3 and 4, the time taken for the water levels to attain equilibrium is reduced in the case of modified gates. Figures 9 and 10 depicts the change in gate opening needed for the canal pools to reach the new steady state condition with radial gates and modified radial gates respectively. The interior gate movements are more complicated than the first gate because the system is trying to counteract the effect of wave movement as fast as possible. It can be seen from Table 3 that the gate opening required for controlling the water level is lesser with modified radial gates and the time needed to attain this is also considerably reduced (1.2-1.8 times). 


\section{RESEARCH ARTICLES}

It is found that change in gate opening is negative for the first gate and positive for all other gates (Table 4). The explanation for this control action is that the system is preventing water from entering the canal pools at the upstream end by decreasing the opening of gate 1 , but at the same time the excess water is drained out to the tail end reservoir by opening the other gates. The water levels shows that the canals do not overtop when controlled and the gate openings do not exceed the possible range. The simulation results indicate that the canal system can be effectively controlled using MPC controller.

\section{Conclusion}

The Saint-Venant equations are used to model the un-

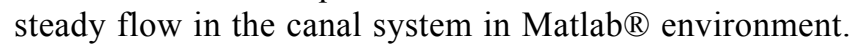
These are approximated to LTI system which is expressed as a function of state variables and control variables. The control variable chosen is the gate opening $(u)$ and has provided adequately reliable results. In distant downstream control strategy, the target depth $\left(y_{t}\right)$ is at the downstream end of the pool and any change required in the target depth $(\Delta y)$ is carried out by adjusting the gate upstream of the pool. This results in minimum water loss in the canal system. Automatic operation of sluice gates is simulated using MPC with maximum and minimum bounds on the gate opening. The canal system was modeled with two types of control structures. The first set of simulation considered radial gates as control structures, while the second one considered the modified radial gate for controlling the canals. The simulation results show that with the modified geometry, the convergence is attained at a better rate and the gate opening required for equilibrium condition is also reduced. The results prove that the proposed control algorithm achieves good control performance which can lead to better irrigation water management.

1. van Overloop, P. J., Clemmens, A. J., Strand, R. J., Wagemaker, R. M. J. and Bautista, E., Real-time implementation of model predictive control on Maricopa-Stanfield irrigation and drainage district's WM canal. J. Irrig. Drain. Eng., 2010; https://doi.org/ 10.1061/(ASCE)IR.1943-4774.0000256.

2. Wahlin, B. T. and Clemmens, A. J., Automatic downstream waterlevel feedback control of branching canal networks: theory. J. Irrig. Drain. Eng., 2006; https://doi.org/10.1061/(ASCE)07339437(2006)132:3(198).

3. Malaterre, P. O. and Baume, J. P., Modeling and regulation of irrigation canals: existing applications and ongoing researches. In Systems, Man, and Cybernetics. IEEE Int. Conf., 1998, 4, 38503855 .

4. Clemmens, A. J., Kacerek, T. F., Grawitz, B. and Schuurmans, W., Test cases for canal control algorithms. J. Irrig. Drain. Eng., 1998; https://doi.org/10.1061/(ASCE)0733-9437(2006)132:3(198).

5. Balogun, O. S., Hubbard, M. and De Vries, J. J., Automatic control of canal flow using linear quadratic regulator theory.
J. Hydraul. Eng., 1998; https://doi.org/10.1061/(ASCE)07339429(1988)114:1(75).

6. Reddy, J. M., Local optimal control of irrigation canals. J. Irrig. Drain. Eng., 1990; https://doi.org/10.1061/(ASCE)0733-437(1990)116:5(616)

7. Seatzu, C., Design and robustness analysis of decentralized constant volume-control for open-channels. Appl. Math. Model., 1999; https://doi.org/10.1016/S0307-904X(98)10094-X.

8. Seatzu, C., Decentralized controllers design for open-channel hydraulic systems via eigen structure assignment. Appl. Math. Model., 2000; https://doi.org/10.1016/S0307-904X(00)00025-1.

9. Seatzu, C. and Usai, G., A decentralized volume variations observer for open channels. Appl. Math. Model., 2002; https://doi. org/10.1016/S0307-904X(02)00055-0.

10. Qing-Song, Q. and Yang, K. L., Modeling unsteady open-channel flow for controller design. J. Irrig. Drain. Eng., 2010; https://doi.org/10.1061/(ASCE)IR.1943-4774.

11. Litrico, X. and Fromion, V., Simplified modeling of irrigation canals for controller design. J. Irrig. Drain. Eng., 2004; https://doi.org/10.1061/(ASCE)0733-9437(2004)130:5(373).

12. Litrico, X., Fromion, V., Baume, J. P., Arranja, C. and Rijo, M., Experimental validation of a methodology to control irrigation canals based on Saint-Venant equations. Control Eng. Pract., 2005; https://doi.org/10.1016/j.conengprac.2004.12.010.

13. van Overloop, P. J., Model predictive control on open water systems. Ph D thesis, Technical University, Delft, The Netherlands, 2006.

14. Sepúlveda, C., Instrumentation, Model identification and Control of an Experimental Irrigation canal. Ph D thesis, Universitat Politècnica de Catalunya, Barcelona Tech, Barcelona, Spain, 2007.

15. Weyer, E., Decentralised PI control of an open water channel. IFAC Proc., 2002, 35(1), 95-100.

16. Ooi, S. K. and Weyer, E., Control design for an irrigation channel from physical data. Control Eng. Pract., 2008, https://doi.org/10.1016/j.conengprac.2008.01.004.

17. Horváth, K., Galvis, E., Valentín, M. G. and Rodellar, J. B., Is it better to use gate opening as control variable than discharge to control irrigation canals? J. Irrig. Drain. Eng., 2015; https://doi.org/10.1061/(ASCE)IR.1943-4774.0000798.

18. $\mathrm{Xu}, \mathrm{M}$., Model predictive control of an irrigation canal using dynamic target trajectory. J. Irrig. Drain. Eng., 2016, 143(3), B4016004.

19. Menon, J. and Mudgal, B. V., Experimental determination of contraction coefficient and velocity coefficient for radial gates with elliptical lips. Sadhana-Acad Proc. Eng. Sci., 2018; https://doi.org/10.1007/s12046-018-0818-x.

20. Chaudhry, M. H., Open-channel flow, Springer Science and Business Media, 2007, pp. 333-339.

21. Buyalski, C. P., Ehler, D. G., Falvey, H. T., Rogers, D. C. and Serfozo, E. A., Canal Systems Automation Manual: Volume 1, United States Department of the Interior, Bureau of Reclamation, 1991.

22. Bemporad, A., Manfred, M. and Lawrence, R. N., Model Predictive Control Toolbox 3 User's Guide, The Mathworks, 2010.

23. Speerli, J. and Hager, W. H., Irrotational flow and real fluid effects under planer gates. J. Hydraul. Eng., 1999; https://doi.org/ 10.1061/(ASCE)0733- 9429(1999)125:2(208).

ACKNOWLEDGEMENT. This work was supported by the Prime Minister's Fellowship Scheme for Doctoral Research, a PPP initiative jointly promoted by SERB and Confederation of Indian Industry, India.

Received 10 October 2019; revised accepted 7 January 2020

doi: $10.18520 / \mathrm{cs} / \mathrm{v} 118 / \mathrm{i} 8 / 1255-1264$ 